\title{
Grinding tools made of grains with controlled shape and orientation
}

\author{
Alexander Korotkov ${ }^{1, *}$, and Vitaly Korotkov ${ }^{1}$ \\ ${ }^{1}$ Kuzbass State Technical University. named after T.F. Gorbachev
}

\begin{abstract}
The cutting elements of the grinding tools are grains. But only a small part of the grains participates actively in the cumulative cutting process. Each grain has its own arbitrary shape and a chaotic arrangement in the body of the instrument. As a consequence, the geometry of the cutting part of the grains varies over a wide range and this greatly reduces the performance of grinding tools. A new class of tools and technology for their manufacture, in which the shape and orientation of the used grains is controlled, is proposed. The choice of a certain grains shape is ensured by separating the initial mass of the abrasive in a vibratory way into a series of fractions with the same grain form. Orientation of the grains is achieved by applying an electrostatic effect that regulates the grains position in the tool. The pilot batches of grinding wheels - cutting, peeling, petal are designed and manufactured, as well as grinding skins and belts with controlled shape and orientation of the grains. Circles and tapes underwent comparative tests with standard tools and showed significant advantages in operation.
\end{abstract}

\section{Introduction}

Grains are the main cutting elements of grinding tools. The efficiency of each grain affects the performance of tools in general. It was found out that only a small part of the grains actively participates in the cutting process. Many grains that have an unfavorable geometry for cutting do not cut metal, but only deform and heat it. In this case, under the action of cutting forces, the grains split and fly out of the bundle $[1,2,3,4,5]$. Geometry of grains is determined by their shape and location in the body and on the surface of the instrument.

The grains shape in most standard tools varies over a wide range from isometric to lamellar varieties. The geometry of the cutting wedges formed by them and, consequently, their cutting power depends on the configuration of the grains [6]. Two ways are used to obtain grains of a specific shape: direct production of grains with a given shape (spherical corundum and form-corundum) and separation of grains with the required form from the total mass of the abrasive [7]. To isolate the grinding grains with a certain shape from the total mass of grinding grains, a vibration method is most often used, based on the rolling of grains with an inclined vibrating plane, which sets them different motion paths $[8,9]$.

The specific arrangement of grains in grinding tools can be achieved by placing them in an electrostatic field, causing the grain to rotate with sharp edges toward the electrodes [10].

\footnotetext{
* Corresponding author: korotkov.a.n@mail.ru
} 
Targeted variation with one or two factors simultaneously (shape and orientation of the grains) allows creating a new class of grinding tools with increased operational capabilities [11].

To realize this goal, in this work, designs of experienced grinding tools with controlled shape and orientation of grains have been designed and technologies for their production have been developed. Experimental batches of experimental grinding tools which have passed comparative tests and have shown higher operational capabilities, than standard tools.

\section{Experimental research techniques}

In these studies, a vibration method has been selected for the separation of abrasive mass on the basis of the shape due to its high selectivity and the accuracy of separation. The method allows to divide the initial abrasive mass into 10 - 14 fractions with different grains shape. The optimal grains shape is determined experimentally for each tool and type of grinding. At the same time, the shape control of the grains is carried out using special software using a microscope and a scanner [12]. For the quantitative identification of the shape of the grains, a form factor equal to the ratio of the inscribed and circumscribed circumferences on a planar projection of the grain or the ratio of the diameters of the inscribed and described spheres in the volumetric projection of the grain was used. At least 50-100 separate grains were measured, and the result was obtained as an average value for the fraction under consideration.

The electrostatic method of grain orientation is realized on a special installation with concentric, radial and oblique arrangement of electrodes. This allowed to lay the grain in the body of the grinding wheels parallel to the cutting plane, perpendicular or oblique to it. For grinding belts and petal circles, the orientation of the grains was also carried out by using special installations and based on the electrostatic effect $[13,14]$.

The manufacturing techniques of the experimental tools included the technological operations realized for standard tools. Except for the addition of operations for the allocation of grains of a certain shape and purposeful tilt of them in the tools. For the application of these technologies, a set of special devices, devices and equipment has been developed and selected. These include: a mixer for the preparation of a mixture of grains with a bunch, a hydropress for shaping grinding wheels, an electric furnace for heat treatment of wheels, a compact line for the manufacture and heat treatment of grinding skins [15].

Experimental batches of experimental cut-off, stripping, petal circles and grinding belts that have been tested for a number of operational parameters in comparison with standard grinding tools have been made $[16,17,18,19]$.

\section{Results and discussion}

The results of comparative tests of cut-off grinding wheels with different shapes and different orientations of grains are shown in the graphs of Fig. 1 and Fig. 2 (cutting capability, Qm). 


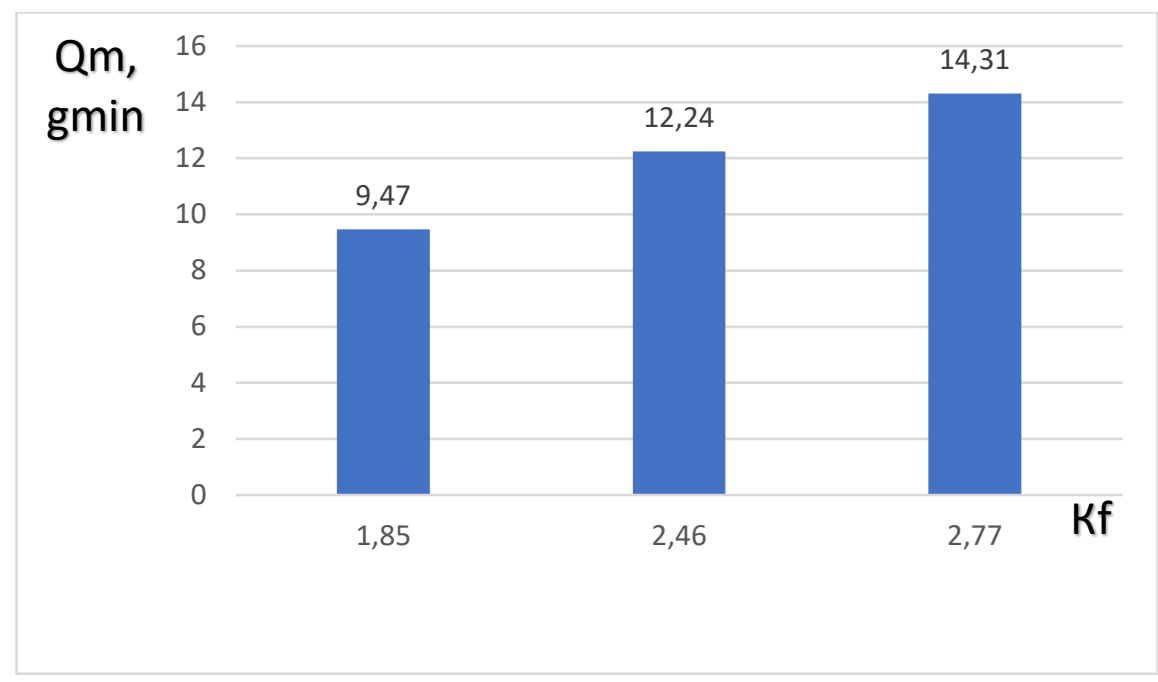

Fig. 1. Cutting capability of cut-off grinding wheels with different shapes of grains on Steel 10

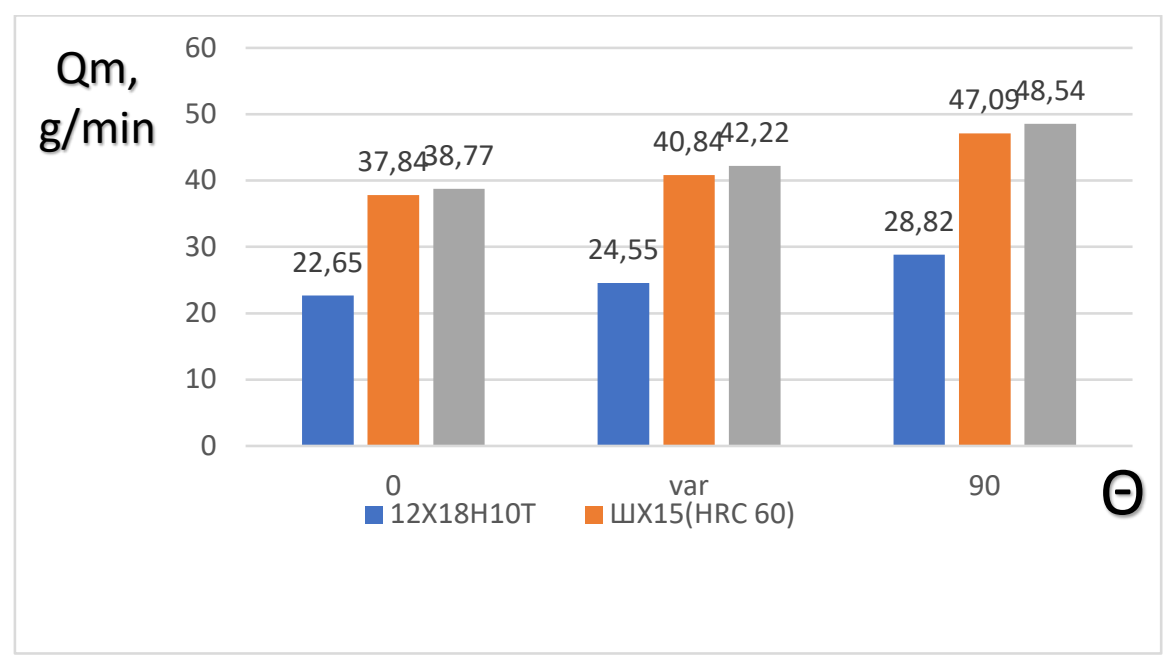

Fig. 2. Cutting capability of cutting wheels for tangential $\left(0^{\circ}\right)$ and radial arrangement of the grains $\left(90^{\circ}\right)$ in comparison with the standard circles (var) for the three grades of steel 12X18H10T, ШX15, Steel 10 .

The results of comparative tests of grinding wheels with different shapes of grains $(\mathrm{Kf}=$ $1.28, \mathrm{Kf}=1.52, \mathrm{Kf}=1.81, \mathrm{Kf}=2.3$ ) are shown in the graph of Fig. 3. (cutting capability, Qm) 


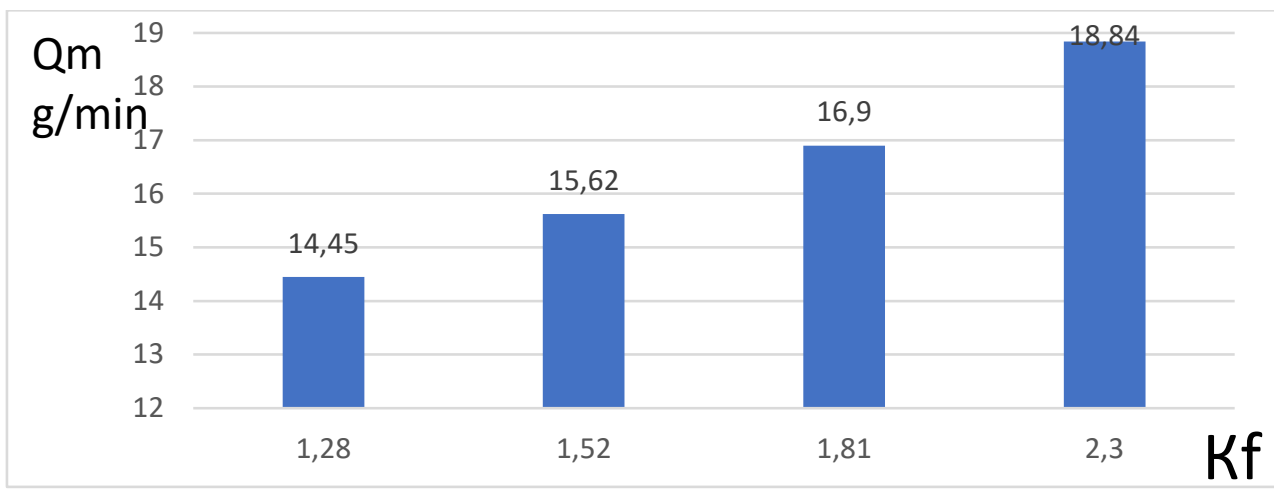

Fig. 3. Cutting ability of grinding wheels with different shape of grains: $\mathrm{Kf}=1,28 ; \mathrm{Kf}=1.52 ; \mathrm{Kf}=$ 1,81 (unsorted grain), $\mathrm{Kf}=2,3$ when processing welded seams on steel $09 \mathrm{G} 2 \mathrm{~S}$.

The results of comparative tests of petal grinding wheels with different shape of grains $(\mathrm{Kf}=1,2, \mathrm{Kf}=1.6, \mathrm{Kf}=1.75, \mathrm{Kf}=2.2)$ are shown in the graph of Fig. 4. (cutting ability, Qm).

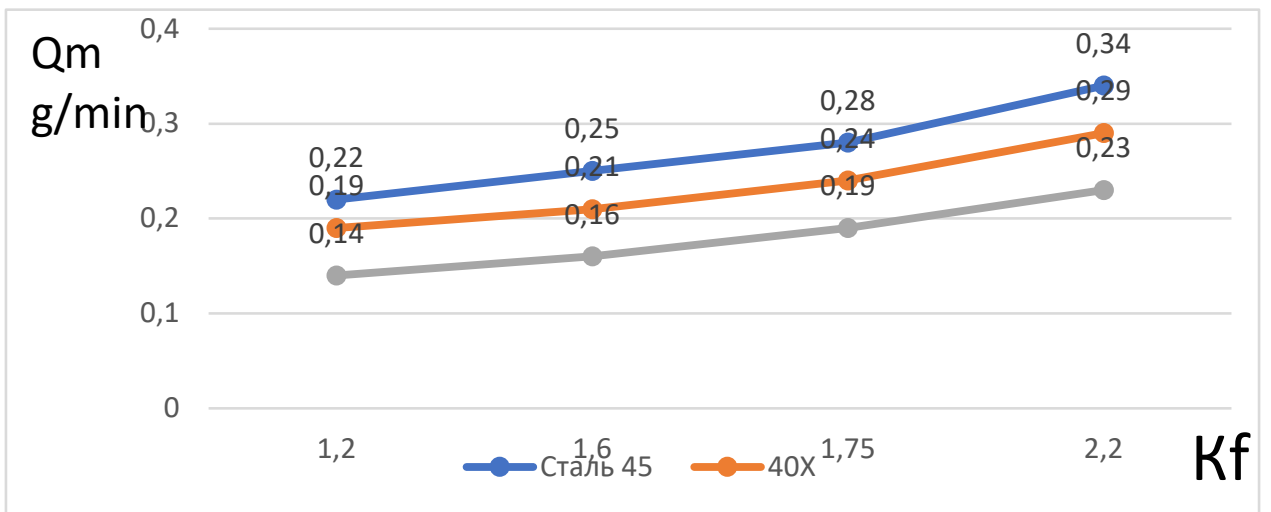

Fig. 4. Cutting power of petal grinding wheels with different shape of grains: $\mathrm{Kf}=1,2 ; \mathrm{Kf}=1.6 ; \mathrm{Kf}=$ 1,75 (standard tool), $\mathrm{Kf}=2,2$ at processing steels: steel 45, 40X, ШX15.

The results of comparative testing of grinding bands with different grain shapes $(\mathrm{Kf}=$ $1.14, \mathrm{Kf}=1.56, \mathrm{Kf}=1.79, \mathrm{Kf}=2.27)$, and different grain tilts $\left(\gamma=90^{\circ} ; \gamma=75^{\circ}\right)$ are shown in the graph of Fig. 5. (cutting capability, Qm).

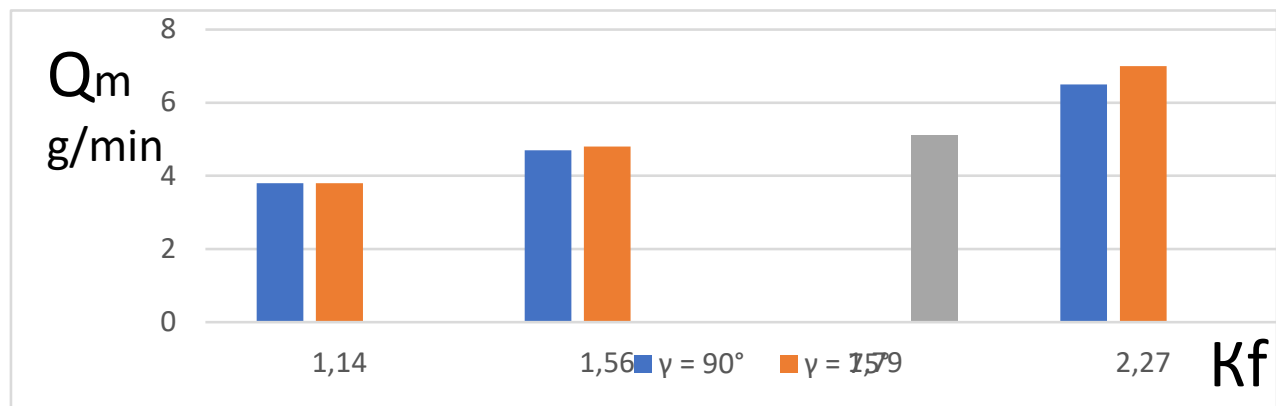

Fig. 5. Cutting capacity of grinding belts with different shape of grains: $\mathrm{Kf}=1,14 ; \mathrm{Kf}=1.56 ; \mathrm{Kf}=$ 1.79 (standard tool), $\mathrm{Kf}=2.27$ and different orientation of the grains: $\gamma=90^{\circ} ; \gamma=75^{\circ}$ on St3 
The presented results show that:

- using needle-plate-like varieties (high values of the form factors) gives an increase in cutting ability by $17 \%$ (for cutting wheels), by $12 \%$ (for grinding wheels), by $21 \%$ (for petal circles), in comparison with standard tools 27 - 37\% (for grinding belts);

- radial orientation $\left(90^{\circ}\right)$ of grains in grinding tools gives an increase in cutting ability depending on the steel grade by $15-17 \%$ (for cutting wheels), by $27 \%$ (for grinding belts with a grain orientation of $90^{\circ}$ ) and by $37 \%$ (for grinding belts with a grain orientation of 75 $\left.{ }^{\circ}\right)$.

\section{Conclusions}

1. The performance of grinding tools depends to a large extent on the shape and orientation of the constituent grains. In standard tools, only a small part of the grains actively participates in the grinding process. Therefore, such tools have a relatively low effect of use.

2. The ordering of the shape and orientation of the grains allows to increase significantly the operational capabilities of grinding tools.

3. Designed constructions of experimental tools (cutting, abrasive, petal circles and grinding bands) with a controlled shape and orientation of the grains. Technologies for manufacturing such instruments have been developed and their experimental batches have been manufactured.

4. Experienced instruments underwent comparative tests with standard tools, the input of which was confirmed by increased operational capabilities.

5. For the maximum effective use of grinding tools, it is necessary to differentiate the choice of the shape and orientation of the grains for each grinding event and each tool.

\section{References}

1. Abrasive and diamond processing of materials: reference book (Moscow: Mechanical Engineering, 1977)

2. Degner W., Lutze H., Smejkal E. Spanende Formung: Theorie, Berechnung, Richtwerte, (Carl Hanser Verlag Muenchen Wien,1993)

3. Lal G., Shaw M. Influence of the radius at the top of the abrasive grains on the process of pure grinding. Design and Engineering Technology. Works of American Union of engineers, 97 (1975).

4. Korotkov A.N., Korotkova L.P., Gubaidulina R.H., Effect on grains form on performances of the grinding wheels, Applied Mechanics and Materials, Vol. 682, P. 469-473 (2014)

5. Zaitsev A.G. Influence of the diamond grains arrangement on the process of grinding hard alloys, Bulletin of Machine Building, No. 8. - P. 71-72 (1877)

6. Lukshin V. Evaluation of Abrasive Grain Form. Applied Mechanics and Materials, 682 (2014). doi: 10.4028 / www.scientific.net / AMM.682.148. eid = 2-s2.0-84921879064

7. Abrasive materials and tools. Catalog (M .: VNIITEMR, 1986) 